\title{
Prostatic adenocarcinoma presenting with metastases to the testis and epididymis: A case report
}

\author{
JIN ZHANG ${ }^{1 *}$, MEI DONG ${ }^{2 *}$, XIAOLEI HU ${ }^{1}$, LIN LIU $^{1}$, SHEN LI $^{1}$, CHAO LI $^{1}$, LIJUN YANG ${ }^{1}$, \\ YONGQIANG XIAO ${ }^{1}$, SHUJIAN PANG ${ }^{1}$ and CHUAN WANG $^{3}$ \\ ${ }^{1}$ Department of Urology, The First Hospital of Shijiazhuang; \\ ${ }^{2}$ Department of Surgery, The Affiliated Hospital of Hebei Science and Technology University; \\ ${ }^{3}$ Department of Pharmacology, Hebei Medical University, Shijiazhuang, Hebei, P.R. China
}

Received September 23, 2014; Accepted October 14, 2015

DOI: $10.3892 / 01.2015 .3920$

\begin{abstract}
Few cases of testicular metastases from prostate carcinoma have been reported, and asymptomatic metastases of prostate carcinoma to both the testis and epididymis are extremely rare. The current study presents the case of a 69 -yearold male with testicular and epididymal metastases from prostate carcinoma. The patient was admitted to The First Hospital of Shijiazhuang with a 2-year history of lower urinary tract symptoms. Digital rectal examination revealed an enlarged multinodular prostate, and the serum prostate-specific antigen (PSA) level was $>100 \mathrm{ng} / \mathrm{ml}$. Magnetic resonance imaging showed prostate carcinoma with seminal vesicle involvement. A prostate biopsy showed prostate gland adenocarcinoma. The Gleason score was $3+3$. The immunohistochemistry results were as follows: Prostatic acid phosphatase (+++), PSA (+++), P504s (+++), p63 (-) and cytokeratin 34ßE12 (-), with a Ki-67 of $\sim 5 \%$. The patient was treated with a bilateral orchiectomy. The testicular pathology showed that the right testis and epididymis were invaded with metastatic adenocarcinoma. The left testis and epididymis were normal. The patient was treated with conventional flutamide endocrine therapy. At present the patient remains in a stable condition after 24 months of follow-up.
\end{abstract}

\section{Introduction}

Prostate cancer is the most commonly diagnosed solid malignancy that occurs in the Western male population, with

Correspondence to: Dr Jin Zhang, Department of Urology, The First Hospital of Shijiazhuang, 36 Fanxi Road, Shijiazhuang, Hebei 050011, P.R. China

E-mail: drjinzhang@hotmail.com

Dr Chuan Wang, Department of Pharmacology, Hebei Medical University, 361 Zhongshan East Road, Shijiazhuang, Hebei 050017, P.R. China

Email: wangchuan@hebmu.edu.cn

${ }^{*}$ Contributed equally

Key words: prostatic adenocarcinoma, metastasis, testis, epididymis an incidence rate that is continually increasing (1). Prostate cancer is the sixth leading cause of cancer related mortality in males, worldwide (2); annual global mortality rates increased from 156,000 to 256,000 mortalities between 1990 and 2010 (3). Patients diagnosed with prostate cancer usually exhibit one or more symptoms, including frequent urination, nocturia, difficulty starting and maintaining a steady stream of urine, hematuria and dysuria. Prostate cancer is diagnosed by biopsy. Medical imaging may then be performed to determine if the cancer has spread to other parts of the body (4). Approximately $8 \%$ of all prostate cancers are diagnosed at an advanced stage (5). Bone and lung metastases from prostate cancer are common, but metastases to both the testis and epididymis are rare, with a usually poor prognosis (6). The treatments for prostate cancer include a combination of surgery, radiation therapy, hormone therapy and chemotherapy. Patient outcome depends on the patient's age and general medical condition, as well as how aggressive and extensive the cancer is (7). The current study presents the case of a 69-year-old male who was diagnosed with synchronous testicular and epididymal metastases from a high-grade prostate carcinoma, without distant metastasis. To the best of our knowledge, such a case has seldom been described in the literature. Written informed consent was obtained from the patient.

\section{Case report}

In July 2012, a 69-year-old male was admitted to The First Hospital of Shijiazhuang (Shijiazhuang, China) with a 2-year history of lower urinary tract symptoms, including increased frequency of urination, noturia and a weak urinary stream, without dysuria or hematuria. In a routine examination 1 month prior to admittance, it was found that the patient's serum prostate-specific antigen (PSA) level was $>100 \mathrm{ng} / \mathrm{ml}$ (normal range, $<4.0 \mathrm{ng} / \mathrm{ml}$ ). The patient's medical history included 24 years of diabetes treated with insulin (fasting glucose level of $6.55 \mathrm{mmol} / \mathrm{l}$; normal range, 3.89-6.1 mmol/l) and a 20 -year history of hypertension that was treated with benazepril and metoprolol. The patient had undergone a prostate transurethral resection five years previously due to prostate bleeding. The current prostate pathology showed prostatic hyperplasia. The 
patient also had a history of smoking 10 cigarettes per day for 40 years.

Physical examination showed that the right testicle was slightly enlarged and tough, without tenderness. No abnormalities were found in the spermatic cord and left testicle. B-mode ultrasound showed prostatic hyperplasia with calcification (51x63x58 mm). An increased post-void residual urine volume of $110 \mathrm{ml}$ (normal range, 5-12 ml) was noted. The kidneys, ureters, bladder, liver and spleen were normal. Magnetic resonance imaging revealed prostate carcinoma with seminal vesicle involvement. A prostate biopsy revealed prostate gland adenocarcinoma, with a Gleason score of $3+3$ (8). Immunohistochemical staining showed strong positive staining for prostatic acid phosphatase (PAP) $(+++)$, PSA $(+++)$ and P504s (+++), but not for p63 (-)or CK34ßE12 (-) (9). The Ki-67 was $~ 5 \%$. A metastatic evaluation of the chest, abdomen, pelvis, bones, kidneys, ureters, bladder, liver and spleen were negative. The patient was treated with a bilateral orchiectomy. The testicular pathology showed that the right testicle, the tunica albuginea and the epididymis were infiltrated by metastatic adenocarcinoma (Figs. 1 and 2); microscopically, malignant round tumor cells were observed within the interstitium of the testicular parenchyma beneath the capsule. The cells had infiltrated the seminiferous tubules and exhibited a discohesive growth pattern. Immunohistochemical staining once again showed strong positive staining for PAP $(+++)$, PSA $(+++)$ and P504s (+++). The left testis and epididymis were normal.

The patient was treated with ongoing conventional flutamide (250 mg, 3 times/day) endocrine therapy and radiotherapy (60 Gy/30 fractions 5 times/week) for 6 weeks, and currently remains in a stable condition after follow-up for 24 months.

\section{Discussion}

Prostate cancer is a common cancer in older men (10). With changes in life style, diet and environment, as well as the improved detection level, the incidence of prostate cancer has recently increased (11). The majority of prostate cancer is adenocarcinoma, usually occurring in the peripheral zone of the prostate (12). Prostate cancer may spread through the lymph and blood vessels, or through direct invasion to adjacent organs. Blood transfer accounts for $35 \%$ of this spread. The most common sites of metastases are the bones, lungs, liver, pleura and adrenal glands (13), while the occurrence rates of metastases in the testes and epididymis are low. Johansson and Lannes showed that $4 \%$ of metastases to the testes are found incidentally during orchiectomy for advanced prostate carcinoma (14). Following the examination of 24,000 autopsy results, Pienkos and Jablokow reported a testicular metastasis rate of $0.06 \%$ (15). However, asymptomatic metastases of prostate carcinoma to both the testis and the epididymis are extremely rare occurrences; only a small number of cases have been reported previously $(1,2)$. Thon et al (16) reported a case of carcinoma of the prostate in a German patient who exhibited metastases to the testis and epididymis. However, to the best of our knowledge, to date no cases of such have been reported in Asia. Prostate cancer metastasis to the testes usually lacks symptoms and signs, and can only can be incidentally detected during autopsies, or following a bilateral orchiectomy for hormonal management in cases of advanced prostate carcinoma. Prostate carcinoma may spread to

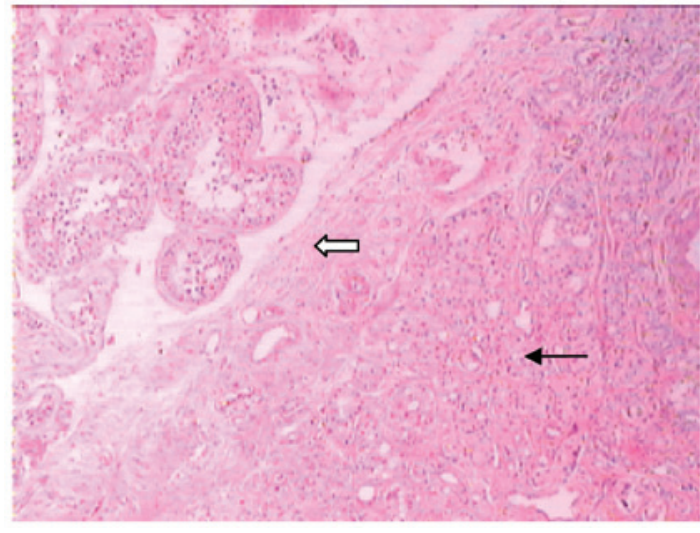

Figure 1. Neoplasm infiltrating the testicular tissue with adenocarcinoma. The white arrow indicates the tunica albuginea, which was invaded by prostatic adenocarcinoma. The black arrow indicates the prostate adenocarcinoma (hematoxylin and eosin staining; magnification, $\mathrm{x} 10$ ).

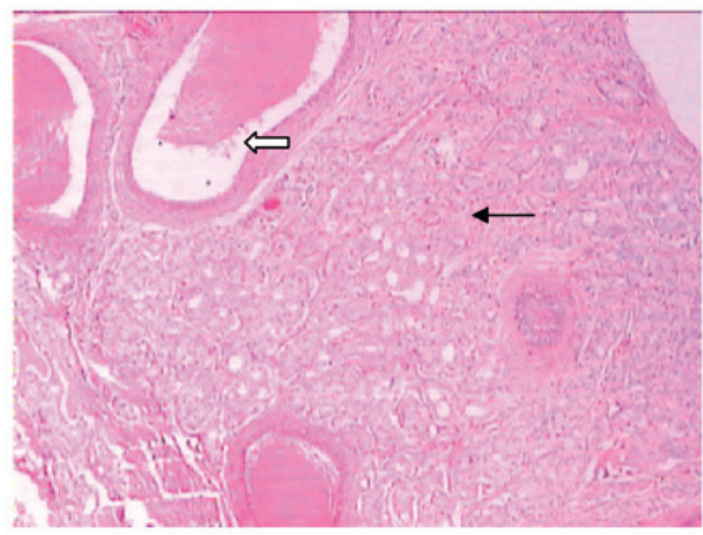

Figure 2. Neoplasm infiltrating the epididymal duct with adenocarcinoma. The white arrow indicates the epididymal duct, with carcinoma invasion around the duct. The black arrow indicates the prostate adenocarcinoma tissue (hematoxylin and eosin staining; magnification, x10).

the testes or epididymis by retrograde venous diffusion, arterial embolism, retrograde lymphatic spread or direct extension via the vas deferens $(14,15)$.

The prognostic significance of testicular metastasis from prostate carcinoma remains unknown. The study by Tu et al suggested that prostate cancer with testicular metastasis is equally sensitive to endocrine and radiation therapy (17). The mean sensitive period for endocrine treatment is 33 months, while the mean lifetime of prostate cancer patients following diagnosis is 78 months (14). The present patient had been treated with endocrine therapy and radiation therapy for 1 month, and the serum PSA level was slowly being reduced. However, after 1 year of treatment with endocrine therapy, the patient's serum PSA level returned to normal. The patient remains under close follow-up.

\section{Acknowledgements}

This study was supported by grants from the National Natural Science Foundation of China (no. 31171097), the Natural Science Foundation of Hebei Province (no. C2014206419), the Hebei Province Overseas Returnees Start-up Fund (no. C2012003031) 
and the Research Project of Science and Technology of Higher Education of Hebei Province (nos. ZD2015007 and Z2015005).

\section{References}

1. Siegel R, Naishadham D and Jemal A: Cancer statistics, 2012. CA Cancer J Clin 62: 10-29, 2012.

2. Jemal A, Bray F, Center MM, Ferlay J, Ward E and Forman D. Global cancer statistics. CA Cancer J Clin 61: 69-90, 2011.

3. Lozano R, Naghavi M, Foreman K, Lim S, Shibuya K, Aboyans V, Abraham J, Adair T, Aggarwal R, Ahn SY, et al. Global and regional mortality from 235 causes of death for 20 age groups in 1990 and 2010: A systematic analysis for the Global Burden of Disease Study 2010. Lancet 380: 2095-2128, 2012.

4. Miller DC, Hafez KS, Stewart A, Montie JE and Wei JT: Prostate carcinoma presentation, diagnosis, and staging: An update form the National Cancer Data Base. Cancer 98: 1169-1178, 2003.

5. Jemal A, Siegel R, Xu J and Ward E: Cancer statistics, 2010. CA Cancer J Clin 60: 277-300, 2010

6. Wang SQ, Mecca PS, Myskowski PL and Slovin SF: Scrota and penile papules and plaques as the initial manifestation of a cutaneous metastasis of adenocarcinoma of the prostate: Case report and review of the literature. J Cutan Pathol 35: 681-684, 2008.

7. Kumar S, Shelley M, Harrison C, Coles B, Wilt TJ and Mason MD: Neo-adjuvant and adjuvant hormone therapy for localized and locally advanced prostate cancer. Cochrane Database Syst Rev 18: CD006019, 2006.

8. Gleason DF and Mellinger GT: Prediction of prognosis for prostatic adenocarcinoma by combined histological grading and clinical staging. J Urol 111: 58-64, 1974.
9. Parwani AV, Marlow C, Demarzo AM, Mikolajczyk SD, Rittenhouse HG, Veltri RW and Chan TY: Immunohistochemical staining of precursor forms of prostate-specific antigen (proPSA) in metastatic prostate cancer. Am J Surg Pathol 30: 1231-1236, 2006.

10. Kessler ER and Flaig TW: Geriatric considerations in the treatment of advanced prostate cancer. F1000 Prime Rep 6: 33, 2014.

11. Antczak A, Kluźniak W, Wokolorczyk D, Kashyap A, Jakubowska A, Gronwald J, Huzarski T, Byrski T, Debniak T and Masojć B: A common nonsense mutation of the BLM gene and prostate cancer risk and survival. Gene 532: 173-176, 2013.

12. Cortesi M, Fridman E, Volkov A, Shilstein SSh, Chechik R, Breskin A, Vartsky D, Raviv G and Ramon J: New prospective for non-invasive detection, grading, size evaluation and tumor location of prostate cancer. Prostate 70: 1701-1708, 2010.

13. Bubendorf L, Schöpfer A, Wagner U, Sauter G, Moch H, Willi N, Gasser TC and Mihatsch MJ: Metastatic patterns of prostate cancer: An autopsy study of 1,589 patients. Hum Pathol 31: $578-583,2000$.

14. Johansson JE and Lannes P: Metastases to the spermatic cord, epididymis and testicles from carcinoma of the prostate-five cases. Scand J Urol Nephrol 17: 249-251, 1983.

15. Pienkos EJ and Jablokow VR: Secondary testicular tumors. Cancer 30: 481-485, 1972.

16. Thon W, Mohr W and Altwein JE: Testicular and epididymal metastasis of prostate cancer. Urologe A 24: 287-290, 1985 (In German).

17. Tu SM, Reyes A, Maa A, Bhowmick D, Pisters LL, Pettaway CA, Lin SH, Troncoso P and Logothetis CJ: Prostate carcinoma with testicular or penile metastases. Clinical, pathologic and immunohistochemical features. Cancer 94: 2610-2617, 2002. 